NASA/TM-2004-213124

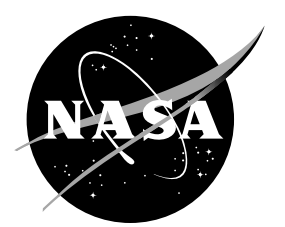

\title{
Design and Control of a Proof-of-Concept Active Jet Engine Intake Using Shape Memory Alloy Actuators
}

Gangbing Song and Ning Ma

University of Houston, Houston, Texas

Nicholas Penney

Ohio Aerospace Institute, Brook Park, Ohio

Todd Barr

Jackson and Tull Aerospace Division, Cleveland, Ohio

Ho-Jun Lee and Steven M. Arnold

Glenn Research Center, Cleveland, Ohio 
Since its founding, NASA has been dedicated to the advancement of aeronautics and space science. The NASA Scientific and Technical Information (STI) Program Office plays a key part in helping NASA maintain this important role.

The NASA STI Program Office is operated by Langley Research Center, the Lead Center for NASA's scientific and technical information. The NASA STI Program Office provides access to the NASA STI Database, the largest collection of aeronautical and space science STI in the world. The Program Office is also NASA's institutional mechanism for disseminating the results of its research and development activities. These results are published by NASA in the NASA STI Report Series, which includes the following report types:

- $\quad$ TECHNICAL PUBLICATION. Reports of completed research or a major significant phase of research that present the results of NASA programs and include extensive data or theoretical analysis. Includes compilations of significant scientific and technical data and information deemed to be of continuing reference value. NASA's counterpart of peerreviewed formal professional papers but has less stringent limitations on manuscript length and extent of graphic presentations.

- TECHNICAL MEMORANDUM. Scientific and technical findings that are preliminary or of specialized interest, e.g., quick release reports, working papers, and bibliographies that contain minimal annotation. Does not contain extensive analysis.

- CONTRACTOR REPORT. Scientific and technical findings by NASA-sponsored contractors and grantees.
- CONFERENCE PUBLICATION. Collected papers from scientific and technical conferences, symposia, seminars, or other meetings sponsored or cosponsored by NASA.

- SPECIAL PUBLICATION. Scientific, technical, or historical information from NASA programs, projects, and missions, often concerned with subjects having substantial public interest.

- TECHNICAL TRANSLATION. Englishlanguage translations of foreign scientific and technical material pertinent to NASA's mission.

Specialized services that complement the STI Program Office's diverse offerings include creating custom thesauri, building customized databases, organizing and publishing research results ... even providing videos.

For more information about the NASA STI Program Office, see the following:

- Access the NASA STI Program Home Page at http://www.sti.nasa.gov

- E-mail your question via the Internet to help@sti.nasa.gov

- Fax your question to the NASA Access Help Desk at 301-621-0134

- Telephone the NASA Access Help Desk at 301-621-0390

- Write to:

NASA Access Help Desk

NASA Center for AeroSpace Information 7121 Standard Drive

Hanover, MD 21076 
NASA/TM-2004-213124

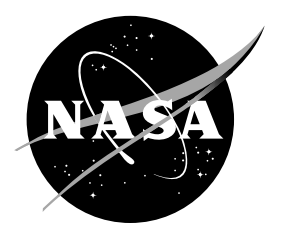

\section{Design and Control of a Proof-of-Concept Active Jet Engine Intake Using Shape Memory Alloy Actuators}

Gangbing Song and Ning Ma

University of Houston, Houston, Texas

Nicholas Penney

Ohio Aerospace Institute, Brook Park, Ohio

Todd Barr

Jackson and Tull Aerospace Division, Cleveland, Ohio

Ho-Jun Lee and Steven M. Arnold

Glenn Research Center, Cleveland, Ohio

National Aeronautics and

Space Administration

Glenn Research Center 


\section{Acknowledgments}

The first author would like to thank the support provided by NASA through a grant (NAG3-2827) and NSF through a CAREER grant (0093737).

This report is a formal draft or working paper, intended to solicit comments and ideas from a technical peer group.

This report contains preliminary findings, subject to revision as analysis proceeds.

This work was sponsored by the Low Emissions Alternative

Power Project of the Vehicle Systems Program at the NASA Glenn Research Center.

Available from

NASA Center for Aerospace Information 7121 Standard Drive

Hanover, MD 21076
National Technical Information Service 5285 Port Royal Road Springfield, VA 22100 


\title{
Design and Control of a Proof-of-Concept Active Jet Engine Intake Using Shape Memory Alloy Actuators
}

\author{
Gangbing Song and Ning Ma \\ University of Houston \\ Houston, Texas 77204 \\ Nicholas Penney \\ Ohio Aerospace Institute \\ Brook Park, Ohio 44142 \\ Todd Barr \\ Jackson \& Tull Aerospace Division \\ Cleveland, Ohio 44135 \\ Ho-Jun Lee and Steven M. Arnold \\ National Aeronautics and Space Administration \\ Glenn Research Center \\ Cleveland, Ohio 44135
}

\begin{abstract}
Summary
The design and control of a novel proof-of-concept active jet engine intake using Nickel-Titanium (Ni-Ti or Nitinol) shape memory alloy (SMA) wire actuators is used to demonstrate the potential of an adaptive intake to improve the fuel efficiency of a jet engine. The Nitinol SMA material is selected for this research due to the material's ability to generate large strains of up to 5 percent for repeated operations, a high power-to-weight ratio, electrical resistive actuation, and easy fabrication into a variety of shapes. The proof-of-concept engine intake employs an overlapping leaf design arranged in a concentric configuration. Each leaf is mounted on a supporting bar that rotates upon actuation by SMA wires electrical resistive heating. Feedback control is enabled through the use of a laser range sensor to detect the movement of a leaf and determine the radius of the intake area. Due to the hysteresis behavior inherent in SMAs, a nonlinear robust controller is used to direct the SMA wire actuation. The controller design utilizes the sliding-mode approach to compensate for the nonlinearities associated with the SMA actuator. Feedback control experiments conducted on a fabricated proof-of-concept model have demonstrated the capability to precisely control the intake area and achieve up to a 25 percent reduction in intake area. The experiments demonstrate the feasibility of engine intake area control using the proposed design.
\end{abstract}

\section{Introduction}

Modern aircraft engine intake designs utilize a variety of different shapes and sizes to achieve optimal engine performance under varying operating conditions. Recent research has demonstrated the potential of using smart materials to actively adjust the inlet area of a jet engine to improve fuel efficiency, vehicle flight performance, mission effectiveness, and vehicle life cycle cost (Pitt et al., 2001). Shape memory alloy (SMA) materials represent one of the candidate smart materials to provide the necessary actuation to 
achieve a variable area intake due to the SMAs high power to weight ratio, solid state actuation, and high corrosion resistance.

SMAs refer to a group of alloy materials that have the inherent ability to return to a predetermined shape upon heating. This phenomenon is called the shape memory effect. When a SMA is below its transformation temperature, the material is weak and can easily be plasticly deformed upon loading into a new shape in which the SMA will remain until heated. When the SMA is heated above its transformation temperature, the newly deformed shape is no longer stable since a crystal phase transformation takes place which transforms the SMA to its original shape. During this process, the SMA can provide extremely large restoration forces or large strain recovery. For example, the commonly used SMA material Nitinol, which consists of an alloy of nickel and titanium, is capable of up to 5 percent recovery strain and $500 \mathrm{MPa}$ of restoration stress under repeated operations.

In aerospace applications, the main advantage of SMAs arises from the high power-to-weight ratio in comparison to conventional actuators such as electrical motors or hydraulic actuators. Specific aerospace applications that have been investigated using SMA actuators include: control of a variable area fan nozzle using a SMA bundled cable actuator (Rey et. al., 2001 and Barooah and Rey, 2002); correcting the blade dissimilarities of a helicopter in flight (Epps and Chopra, 2001); changing the airfoil geometry of a fixed wing (Wolf and Gunter, 2001); and a smart inlet for supersonic flight (Pitt et al., 2001).

In this paper, the application of SMA actuators for aerospace applications is extended by presenting a novel proof-of-concept active jet engine intake using Nitinol shape memory alloy wire actuators. The design of the intake model is described and the dynamic performance is examined by conducting openloop tests. A nonlinear sliding-mode based robust controller is implemented for the feedback control design and the system is tested for both position regulation and tracking.

\section{Proof-of-Concept of an Engine Intake}

In order to demonstrate the feasibility of controlling the variable area intake with the Nitinol SMA actuator, a proof-of-concept intake model was designed and fabricated. Figure 1 shows the front view of this model. The model consists of four parts: eight overlapping leaves, eight supporting bars, the cylindrical frame structure, and the SMA wire actuator system.

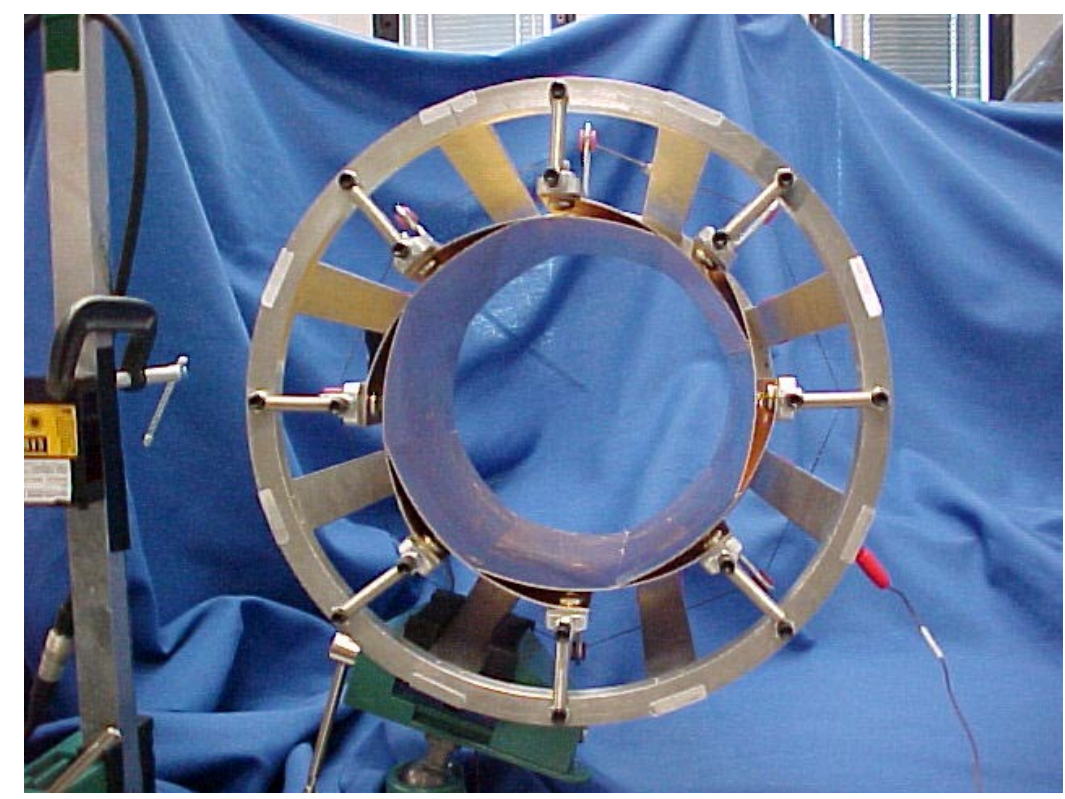

Figure 1.- Model of a proof-of-concept jet engine intake. 


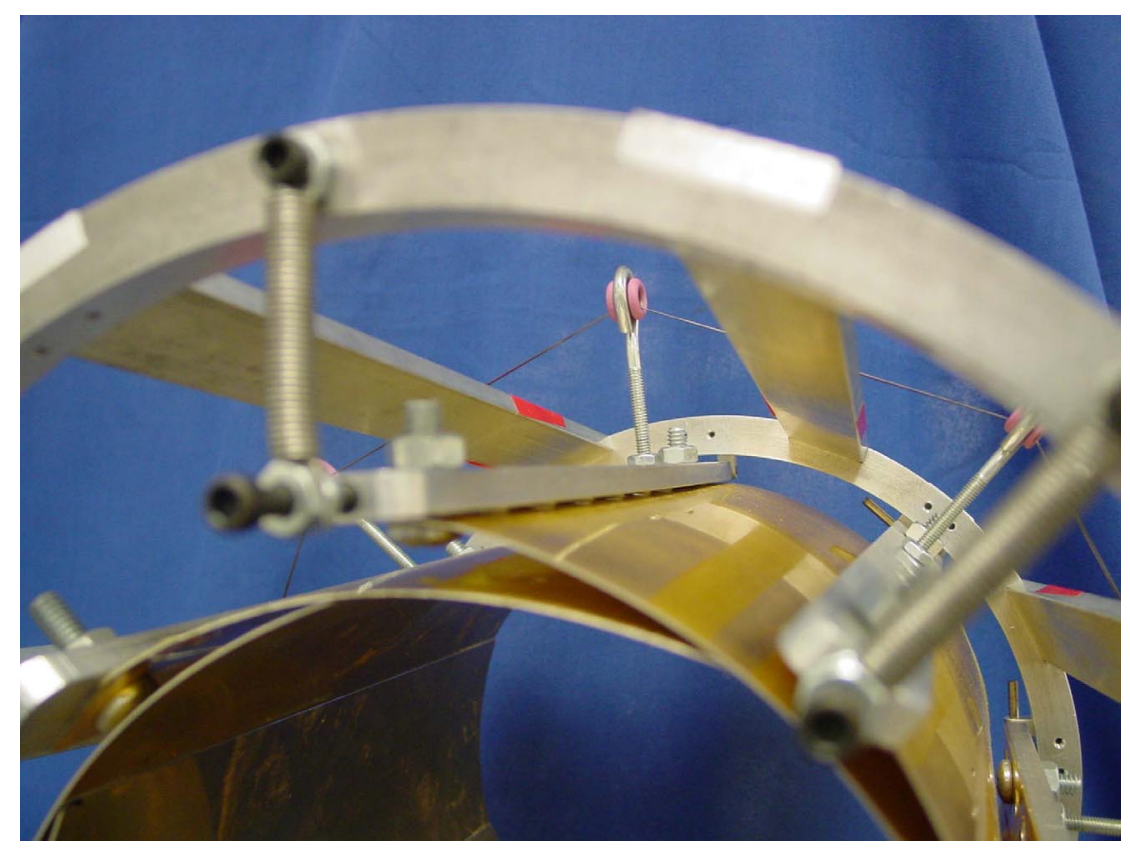

Figure 2.-A close-up view of the supporting bar.

The inner wall of the intake model is constructed by overlapping eight brass leaves in a concentric configuration. Each of the leaves is mounted on a supporting bar. The eight supporting bars are evenly distributed along the circumference of the cylindrical frame structure. One end of each supporting bar is hinged to the frame and the other end is constrained by a pre-strained extension spring. The SMA actuator consists of a group of three Nitinol wires 0.015 inches in diameter that restrains the supporting bars in a ring configuration. Figure 2 illustrates a close-up view of a supporting bar and the associated leaf. In actual operations, the SMA wire group contracts upon electrical resistive heating which causes the supporting bars, along with the leaves, to move inwards toward the center of the cylindrical frame. The result of this action is a corresponding decrease in the overall intake area that also serves to further strain the extension springs. Upon removal of the electrical current, the SMA actuator cools down and the strained extension springs pull the supporting bars back to their original positions in order to recover the original intake area.

The supporting bars also function as a motion amplification mechanism to increase displacements given the 5 percent limited strain provided by the SMA actuator for repeatable operations. Considering the specific geometry of this intake model, the relationship between the tip displacement $y$ of the each supporting bar and the SMA wire's deformation $\Delta x$ is given as

$$
y=\frac{4 L}{L_{1} \sin 22.5^{\circ}} \Delta x
$$

where $L$ is the bar length and $L_{l}$ is the distance from the hinge to the point where the contracting force from the SMA actuator is applied. An appropriate selection of $L$ to $L_{l}$ ratio results in an amplification factor of 5 for the current model. 


\section{Open-Loop Testing of the Intake Model}

An experimental study was developed to conduct open-loop testing and to implement the feedback control of the intake prototype. The experimental setup consists of a digital data acquisition and real-time control system, a laser range sensor, a programmable power amplifier, and the intake model. The laser range sensor is employed to detect the tip displacement of one of the supporting bars, which is subsequently used to calculate the intake area. A programmable power amplifier is used to activate the SMA wires through electric resistive heating.

In the open-loop testing of the intake, two types of input signals were applied to the SMA actuator: a single-square wave signal and a sinusoidal signal. From the response to a single-square wave signal with 30 seconds of heating depicted in figure 3, the maximum displacement at the tip of the supporting bar is $9 \mathrm{~mm}$, corresponding to a 25 percent reduction of the intake area. The SMA actuator requires about 25 seconds to reach its maximum stroke, but takes a longer time period of almost 80 seconds to return to its original area due to the slow heat dissipation. Since the heat dissipation in this experiment occurred mainly through natural convection, the response of the device during the cooling period can be improved by using forced convection.

Figure 4 shows the displacement responses of the supporting bar under actuation from two different sinusoidal signals. The tip position reaches a maximum of $9 \mathrm{~mm}$ for both the $1 / 90 \mathrm{~Hz}$ and $1 / 120 \mathrm{~Hz}$ input signals. However, due to the slower response during cool down, the SMA actuator for the $1 / 90 \mathrm{~Hz}$ signal does have not enough time to completely recover the original area before being reactivated.

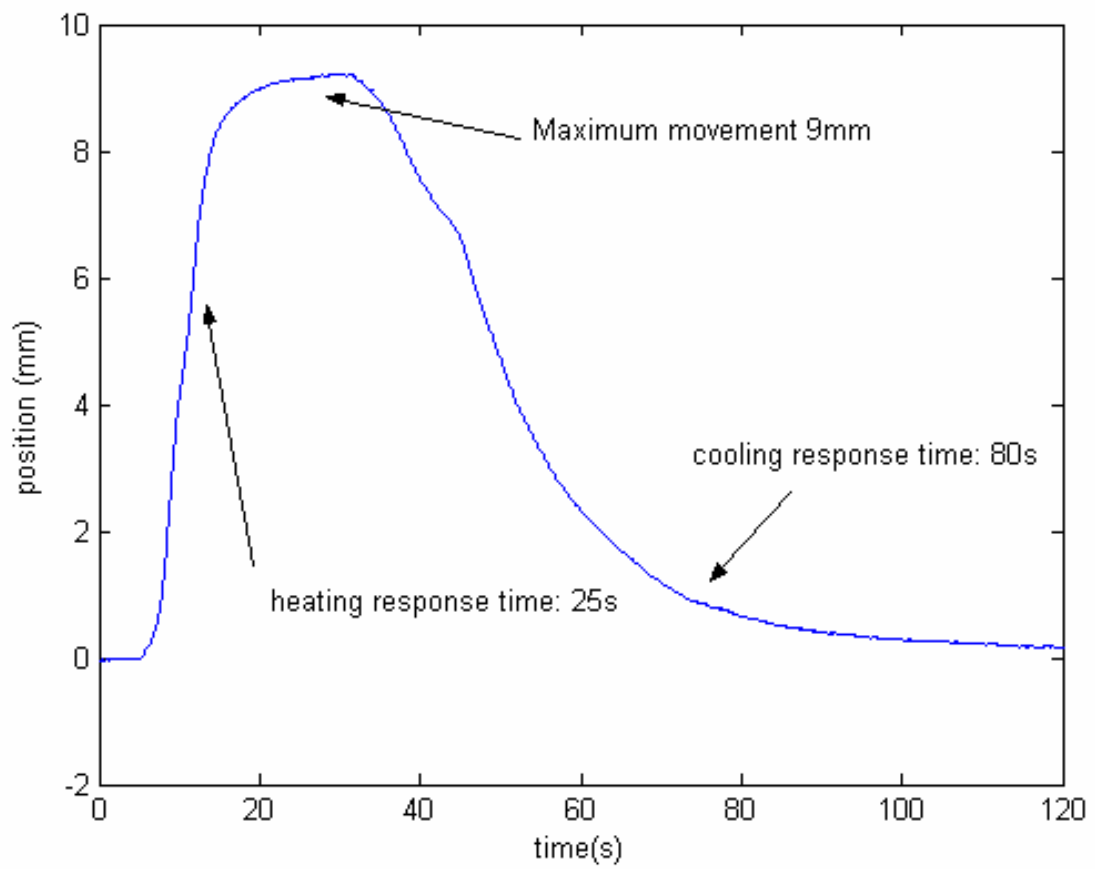

Figure 3.-The position response to a single-square wave input. 


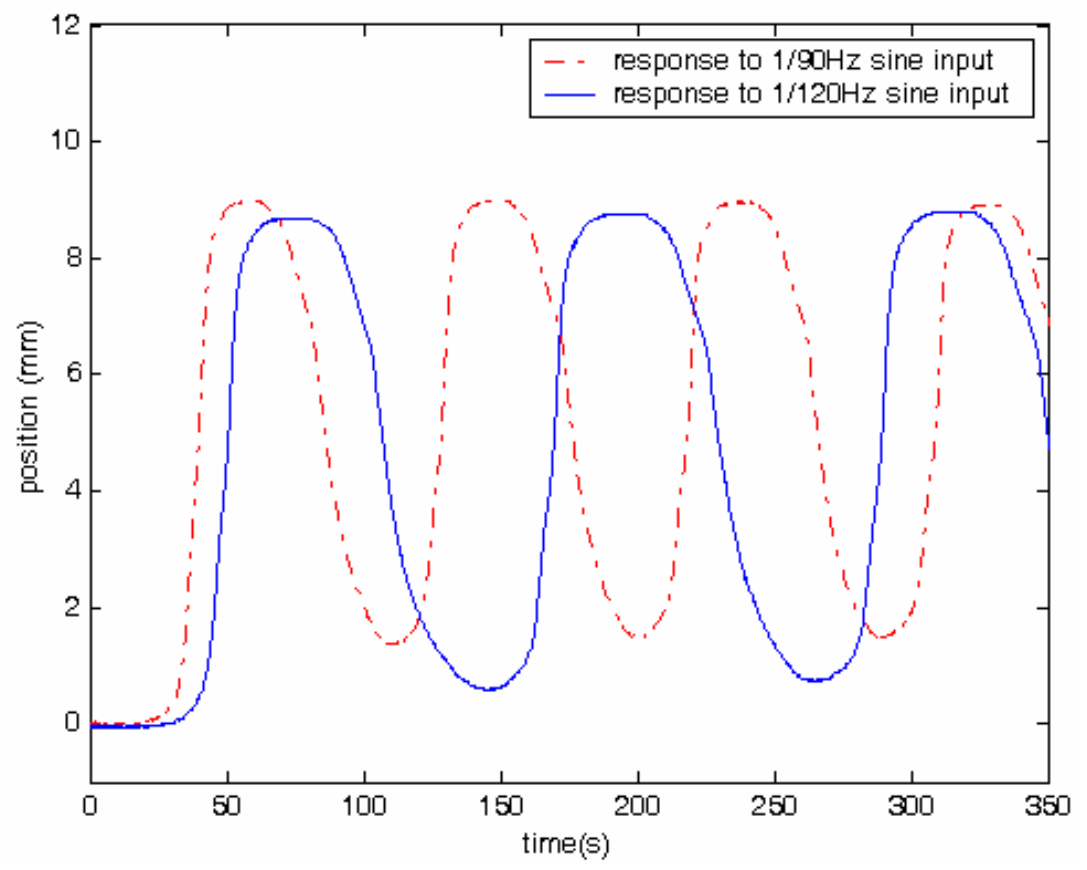

Figure 4.-The position responses to the sinusoidal inputs.

\section{Feedback Control Design}

As mentioned previously, the ability to alter the intake area under different flight conditions provides the potential to improve the performance and efficiency of jet engines. A robust feedback control system is expected to provide a key component to accomplishing this adaptive capability in a stable manner. However, one major obstacle in designing the control system is the hysteretic behavior of the SMA actuator. Figure 5 illustrates the hysteretic relationship between the input voltage signal and tip position of the supporting bar. This inherent hysteresis behavior associated with SMA actuation results from the friction effect between adjunct crystal layers during phase transformation. The implication of the SMAs hysteresis behavior is that inaccurate positioning and potential instability will result from using traditional linear control systems. Thus, in order to achieve high precision and robust stability, a nonlinear control system must be used.

In general, only a few different control algorithms have been investigated for SMA actuators ranging from proportional-integral (PI) control (Majima, Kodama, and Hasegawa, 2001), the H-infinity control (Choi, Han, and Cheong, 2001), and the variable structure control (Grant and Hayward, 1997). In this paper, a nonlinear sliding-mode controller based on a smooth robust controller is used. This type of controller has been successfully utilized for the control of nonlinear systems with uncertainties in applications involving robotic manipulators with joint friction (Song and Mukherjee, 1998) and in SMA wire actuators (Song and Quinn, 2000). The theoretical analysis details for this type of robust controller can be found in Song and Mukherjee (1998).

The sliding mode based robust controller is commonly used to control nonlinear systems. There are three categories of sliding-mode based robust controllers: the bang-bang controller, the saturation controller, and the smooth time-varying controller employing a hyperbolic tangent function with timevarying gain (Song and Mukherjee, 1998). The advantage of the smooth time-varying controller is the ability to guarantee the asymptotical stability while eliminating the chattering that is a drawback of the bang-bang controller. Considering the physical limitations of the position sensor in the developed model, bounded stability will satisfy the requirements for practical applications. Thus, in this paper, the smooth time-varying controller with a fixed gain will be used. 


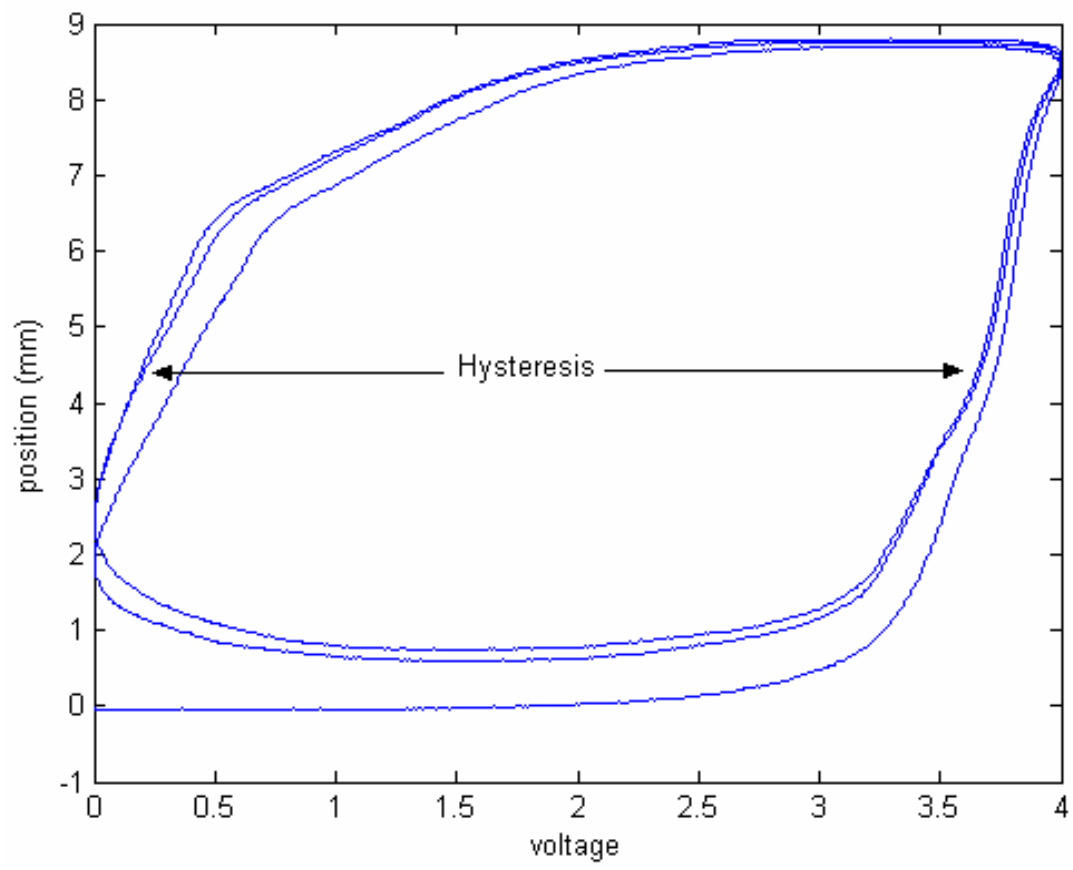

Figure 5.-The hysteretic relationship between the input voltage and the position.

The proposed control law is given by:

$$
u=u_{f}-K r-\rho \operatorname{Tanh}(a r)
$$

where $K$ is a positive constant, $\operatorname{Tanh}(\bullet)$ is a hyperbolic tangent function, and $\rho$ is an estimated upper bound for all the uncertainties associated with the intake actuated by the SMA actuator. The sliding surface is defined as $r=0$ with $r=\dot{e}+\lambda e$, where $e$ is the control error and $\lambda$ is a positive number. $K r$ consists of two components: a proportional action $K \lambda e$, and a derivative action $K \dot{e}$. From equation (2), the control action is composed of three parts: a feedforward action $u_{f}$, a Proportional plus Derivative (PD) action $K r$, and a robust compensator $-\rho \operatorname{Tanh}(a r)$.

The $u_{f}$ is a feedforward action that is defined as

$$
u_{f}=k_{f}\left(T \dot{y}^{d}+y^{d}\right)
$$

where $k_{f}$ is a positive constant gain and $T$ is a positive time constant. The feedforward action is designed to provide the appropriate amount of current required for the SMA actuator to follow the desired path. In general, the actuator system with a bias spring can be approximated as a first order system with a time constant $T$ if the current is considered to be the input and the displacement is the output. However, this first order model does not include the effects of the hysteresis loop. In addition, the effects of the mass of the moving parts and viscous friction in this system are neglected. In this experiment, $T$ can be estimated based on the actuator's step responses. The PD control action helps to increases the damping and to stabilize the system. The robust compensator is used to compensate for the hysteresis loop, as well as other modeling uncertainties and external disturbances. 


\section{Experimental Results}

Real-time feedback control experiments of the adjustable area of the intake model were conducted using the proposed sliding-mode based robust controller. Two tasks were used to evaluate the control performance: position regulation and trajectory tracking.

For the position regulation task, the supporting bar was required to move $5 \mathrm{~mm}$ for a 50 second duration before moving back to the original position as shown in figure 6 . In a second test, the supporting bar was required to move $5 \mathrm{~mm}$ for a 50 second duration and then to hold at the $2 \mathrm{~mm}$ intermediate position for the rest of the test as illustrated in figure 7. From the two figures, the position responses are shown to be much faster than those from the open-loop testing, with relatively small steady state errors. The transient performance is also satisfactory since there is no overshoot. The stability of the system was ensured during the entire position regulation task.

For the trajectory tracking task, the goal was to follow a $1 / 150 \mathrm{~Hz}$ sinusoidal wave. The maximum and minimum values of the wave are $5 \mathrm{~mm}$ and $1 \mathrm{~mm}$, respectively. Figure 8 depicts the actual and desired trajectories and demonstrates that the actual movement of the intake system closely follows the desired trajectory. The tracking error is shown in figure 9 and illustrates the value of root-mean-square error is around $0.03 \mathrm{~mm}$.

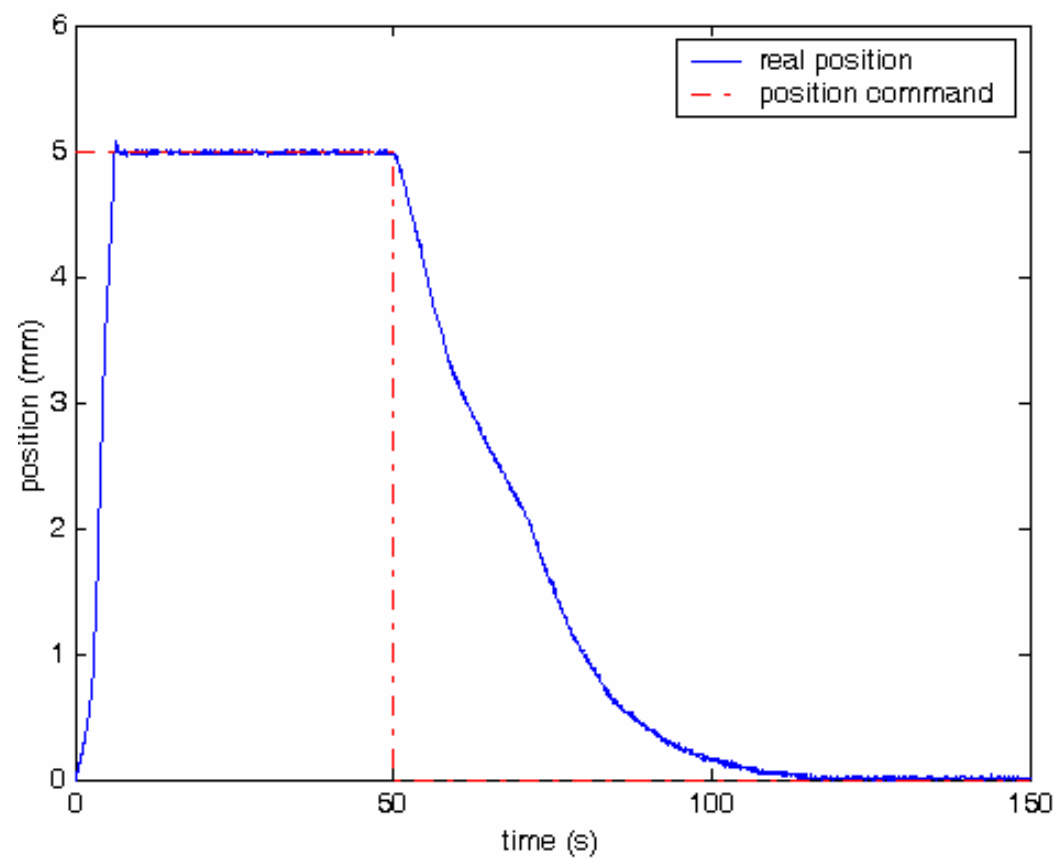

Figure 6.-The controlled position response to a position command. 


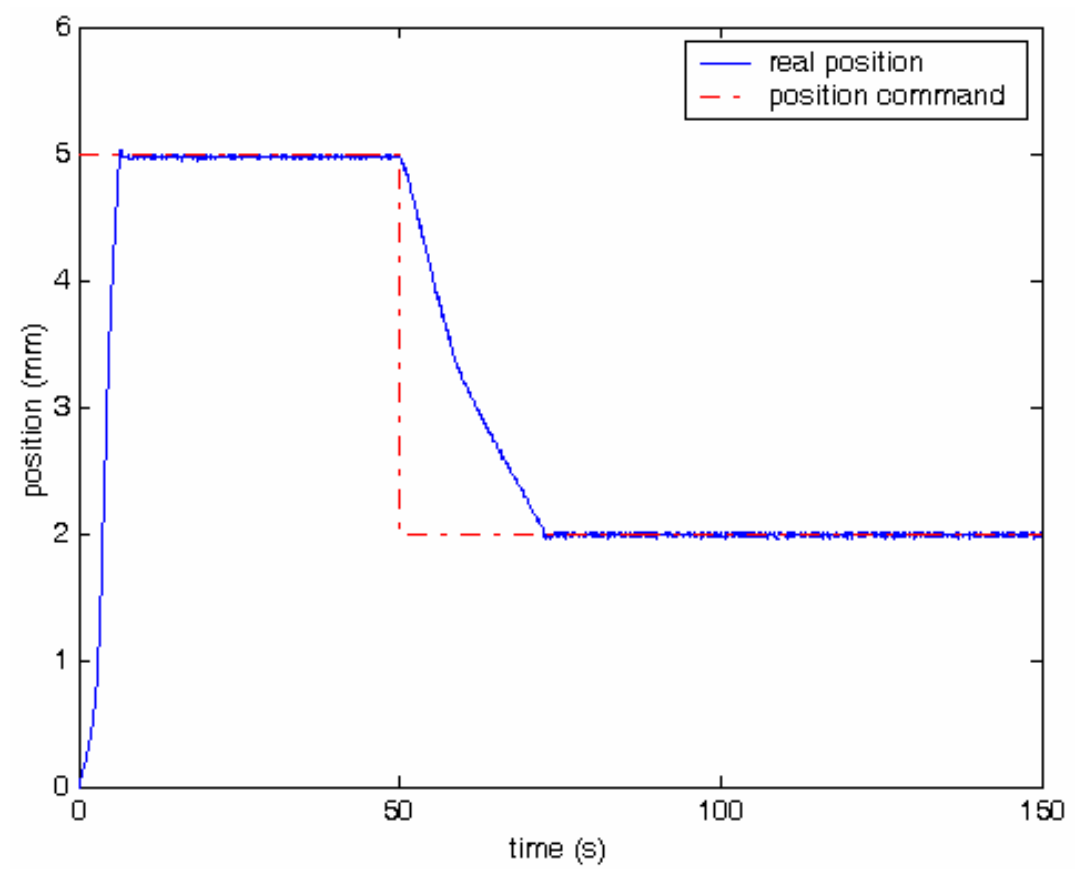

Figure 7.-The controlled position response to two position commands

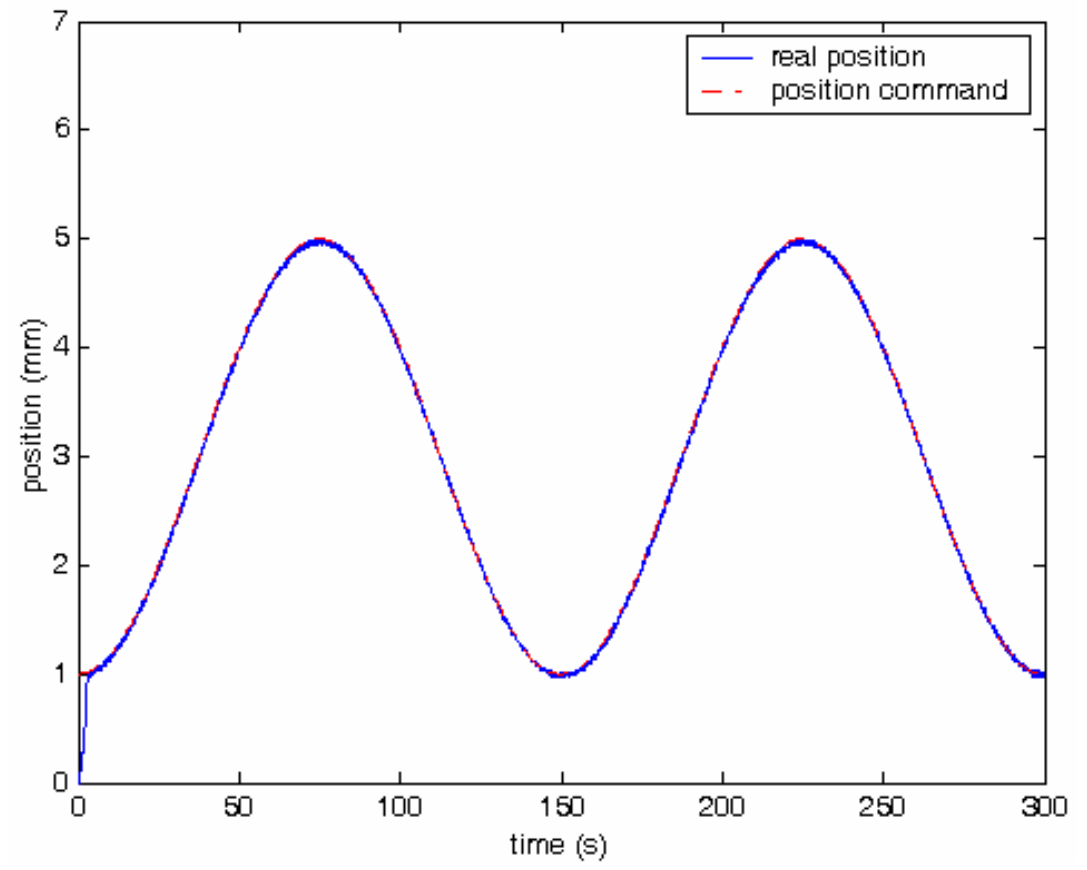

Figure 8.-The actual trajectory following a $1 / 150 \mathrm{~Hz}$ sinusoidal command. 


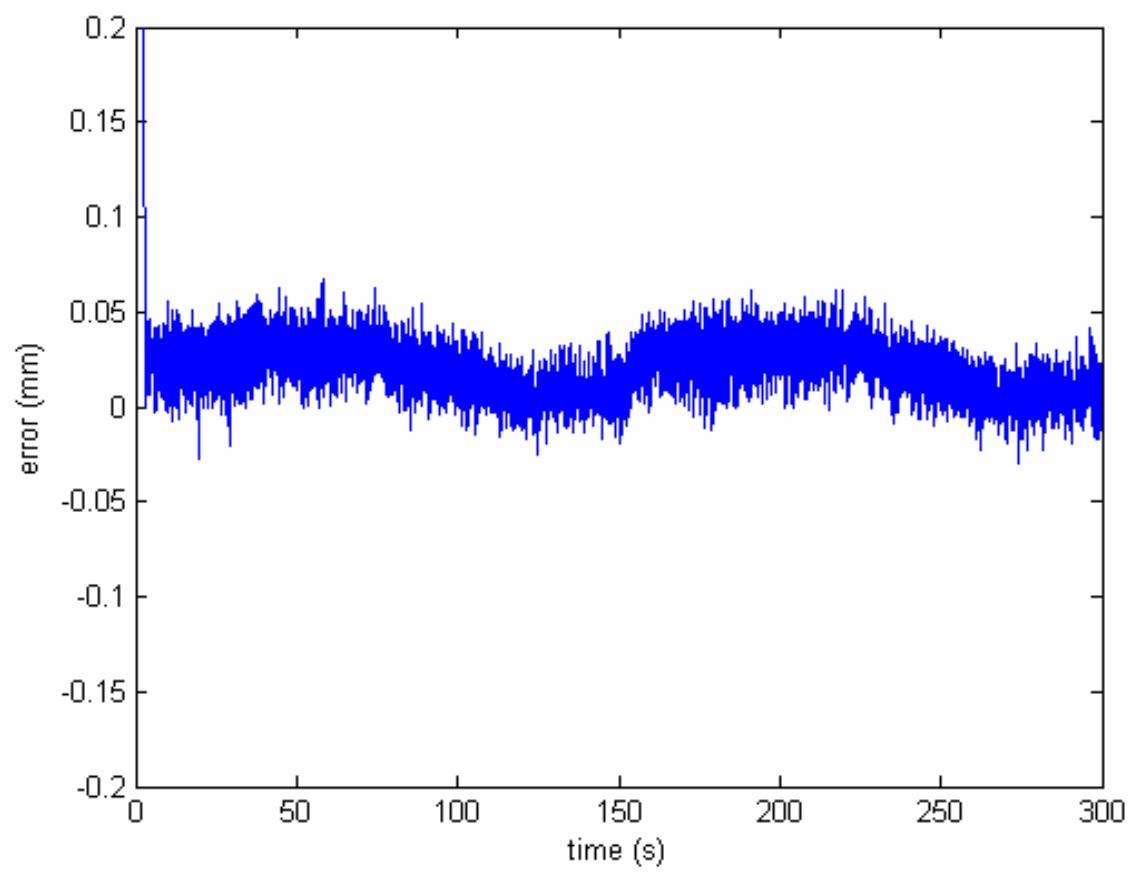

Figure 9.- The tracking error.

\section{Conclusions}

This paper presented a novel design of a SMA wire actuated variable area engine intake, along with corresponding open loop and feedback control experimental tests. The open-loop testing of the intake model was conducted to verify the functionality of the proposed intake model and demonstrated that a 25 percent area reduction of the intake can be achieved. Based on the open-loop testing results, a sliding mode based robust controller was designed and implemented to provide a positioning error of within $0.03 \mathrm{~mm}$. Experiments of both position regulation and trajectory tracking were carried out and the results demonstrated the capability of the controller to achieve the desired control performance.

\section{References}

Barooah P. and N. Rey. 2002. "Closed loop control of a shape memory alloy actuation system for variable area fan nozzle," Proceeding of SPIE International Symposium on Smart Structures and Materials, 4693:384-395.

Choi, S. B., Y. M. Han and C. C. Cheong. 2001. "Force tracking control of a flexible gripper featuring shape memory alloy actuators," Mechatronics, 11(6):677-690.

Epps, J. and I. Chopra. 2001. "In-flight tracking of helicopter rotor blades using shape memory alloy actuators," Smart Materials and Structures, 10(2001): 104-111.

Grant, D. and V. Hayward. 1997. "Variable structure control of shape memory alloy actuator," IEEE Control System Magazine, 17(3): 80-88. 
Majima, S., K. Kodama and T. Hasegawa. 2001. "Modeling of shape memory alloy actuator and tracking control system with the model," IEEE Transaction on Control System Technology, 9(1): 54-59.

Pitt, D. M., J. P. Dune, E. V. White and E. Garcia. 2001. "Wind tunnel demonstration of the SAMPSON smart inlet," Proceeding of SPIE International Symposium on Smart Structures and Materials, 4332:345356.

Rey N. M., G. Tillman, R. M. Miller, T. Wynosky, M. J. Larkin, J. D. Flamm and L.S. Bangert. 2001. "Shape memory alloy actuation for a variable area fan nozzle," Proceeding of SPIE International Symposium on Smart Structures and Materials, 4332:371-382.

Song, G. and R. Mukherjee. 1998. "A comparative study of conventional non-smooth time-invariant and smooth time-varying robust compensators," IEEE Transaction on Control Systems Technology, 6(4): 571576.

Song, G. and D. Quinn. 2000. "Robust tracking control a shape memory alloy wire actuator," Proceedings of Symposium on Control of Vibration and Noise at ASME International Mechanical Engineering Congress \& Exposition.

Wolf, W. and P. Gunter. 2001. "Shape adaptive structures for smart airfoils," IEEE International Conference on Multisensor Fusion and Integration for Intelligent Systems, pp:265-270. 
Public reporting burden for this collection of information is estimated to average 1 hour per response, including the time for reviewing instructions, searching existing data sources, gathering and maintaining the data needed, and completing and reviewing the collection of information. Send comments regarding this burden estimate or any other aspect of this collection of information, including suggestions for reducing this burden, to Washington Headquarters Services, Directorate for Information Operations and Reports, 1215 Jefferson Davis Highway, Suite 1204, Arlington, VA 22202-4302, and to the Office of Management and Budget, Paperwork Reduction Project (0704-0188), Washington, DC 20503.

\begin{tabular}{|l|l|l|}
\hline 1. AGENCY USE ONLY (Leave blank) & $\begin{array}{c}\text { 2. REPORT DATE } \\
\text { June } 2004\end{array}$ & $\begin{array}{r}\text { 3. REPORT TYPE AND DATES COVERED } \\
\text { Technical Memorandum }\end{array}$ \\
\hline
\end{tabular}

\section{TITLE AND SUBTITLE}

5. FUNDING NUMBERS

Design and Control of a Proof-of-Concept Active Jet Engine Intake Using Shape Memory Alloy Actuators

\section{AUTHOR(S)}

Gangbing Song, Ning Ma, Nicholas Penney, Todd Barr, Ho-Jun Lee, and Steven M. Arnold

\section{PERFORMING ORGANIZATION NAME(S) AND ADDRESS(ES)}

National Aeronautics and Space Administration

John H. Glenn Research Center at Lewis Field

Cleveland, Ohio 44135-3191

WBS-22-708-01-15

\section{SPONSORING/MONITORING AGENCY NAME(S) AND ADDRESS(ES)}

National Aeronautics and Space Administration

Washington, DC 20546-0001

8. PERFORMING ORGANIZATION REPORT NUMBER

E-14618

\section{SUPPLEMENTARY NOTES}

Gangbing Song and Ning Ma, University of Houston, Department of Mechanical Engineering, Houston, Texas 77204; Nicholas Penney, Ohio Aerospace Institute, Brook Park, Ohio 44142; Todd Barr, Jackson and Tull Aerospace Division, Cleveland, Ohio 44135; and Ho-Jun Lee and Steven M. Arnold, NASA Glenn Research Center. Responsible person, Ho-Jun Lee, organization code 5930, 216-433-3316.

12a. DISTRIBUTION/AVAILABILITY STATEMENT 12b. DISTRIBUTION CODE

Unclassified - Unlimited

Subject Category: 39

Distribution: Nonstandard

Available electronically at http://gltrs.grc.nasa.gov

This publication is available from the NASA Center for AeroSpace Information, 301-621-0390.

\section{ABSTRACT (Maximum 200 words)}

The design and control of a novel proof-of-concept active jet engine intake using Nickel-Titanium (Ni-Ti or Nitinol) shape memory alloy (SMA) wire actuators is used to demonstrate the potential of an adaptive intake to improve the fuel efficiency of a jet engine. The Nitinol SMA material is selected for this research due to the material's ability to generate large strains of up to 5 percent for repeated operations, a high power-to-weight ratio, electrical resistive actuation, and easy fabrication into a variety of shapes. The proof-of-concept engine intake employs an overlapping leaf design arranged in a concentric configuration. Each leaf is mounted on a supporting bar that rotates upon actuation by SMA wires electrical resistive heating. Feedback control is enabled through the use of a laser range sensor to detect the movement of a leaf and determine the radius of the intake area. Due to the hysteresis behavior inherent in SMAs, a nonlinear robust controller is used to direct the SMA wire actuation. The controller design utilizes the sliding-mode approach to compensate for the nonlinearities associated with the SMA actuator. Feedback control experiments conducted on a fabricated proof-of-concept model have demonstrated the capability to precisely control the intake area and achieve up to a 25 percent reduction in intake area. The experiments demonstrate the feasibility of engine intake area control using the proposed design.

14. SUBJECT TERMS

Smart structures; Smart materials; Shape memory alloys; Intake systems; Engine inlets

\begin{tabular}{|c|c|c|}
\hline $\begin{array}{c}\text { 17. SECURITY CLASSIFICATION } \\
\text { OF REPORT } \\
\text { Unclassified }\end{array}$ & $\begin{array}{c}\text { 18. SECURITY CLASSIFICATION } \\
\text { OF THIS PAGE } \\
\text { Unclassified }\end{array}$ & $\begin{array}{c}\text { 19. SECURITY CLASSIFICATION } \\
\text { OF ABSTRACT } \\
\text { Unclassified }\end{array}$ \\
\hline
\end{tabular}



